\title{
Repeated E-book Reading and Its Contribution to Learning New Words among Kindergartners
}

\author{
Ofra Korat $^{1}$, Olla Kozlov-Peretz ${ }^{1}$, Ora Segal-Drori ${ }^{2}$ \\ ${ }^{1}$ Bar Ilan University, School of Education, Israel \\ ${ }^{2}$ Levinsky Teacher College, Israel \\ Correspondence: Ofra Korat, Bar Ilan University, School of Education, Israel.
}

Received: May 15, 2017

doi:10.11114/jets.v5i7.2498

Accepted: June 11, $2017 \quad$ Online Published: June 18, 2017

URL: https://doi.org/10.11114/jets.v5i7.2498

\begin{abstract}
The contribution of repeated e-book reading with and without word explanation support and its effect on receptive and expressive word learning among preschoolers was examined. Seventy-eight kindergartners were randomly divided into an experimental and a control group. The experimental group received two individual reading sessions of an e-book with a dictionary that provided word explanations. The children clicked on hotspots which provided the explanation two more times. The children thus heard the meaning of the word three times in each session, with a total of six times. Not all difficult words received a dictionary explanation. The control group received the regular kindergarten program. The children's receptive word learning, word explanation and production of focal words were tested pre and post intervention. An improvement in all dependent measures was found post-intervention, compared to the control group. The dictionary in the e-book supported not only receptive word learning, but also word explanation. Words that received a dictionary explanation supported word learning better than words which were not included in the dictionary. Furthermore, receiving support six times was more effective than three times. Educational implications are discussed.
\end{abstract}

Keywords: E-book, repeated reading, learning new words, kindergartners

\section{Introduction}

Shared book reading in early childhood is considered a promising context for promoting children's language, especially vocabulary enrichment. This in turn serves as a support for future reading, reading comprehension and school success (Bus, van IJzendoorn, \& Pellegrini, 1995; Dickinson, Griffith, Golinkoff, \& Hirsh-Pasek, 2012; Lenox, 2013; Sparks \& Reese, 2013). This may be the case since many storybooks for young children involve a written register using infrequent words, which are not part of everyday speech (Evans, Reynolds, Shaw, \& Pursoo, 2011) and which may enrich young children's vocabulary.

Although many studies investigated shared book reading of parents to their young children and the effect of book reading on children's vocabulary (e.g., Bus, van IJzendoorn, \& Pellegrini, 1995; Mol, Bus, de Jong, \& Smeets, 2008; Scarborough \& Dobrich, 1994), the parents' role in this process is not sufficiently clear. Some recent studies that addressed this issue showed that parents explained only few words to their children during the reading sessions (Evans et al., 2011; Hindman, Skibbe, \& Foster, 2014). It was suggested that children's word learning occurs indirectly, due to the text context, and not directly by being told the definition (Penno, Wilkinson, \& Moore, 2002). The National Reading Panel (NICHD, 2000) recommended direct support for learning new words, such as repetition of words, providing explanations, embedding new words in meaningful contexts, and offering children an active role in this process. The panel also suggested that technology tools should be used to foster children's vocabulary.

One of the technological products which may support vocabulary enrichment is the e-book. E-books are becoming increasingly common for children (Guernsey, Levine, Chiong, \& Severns, 2014) and can provide an opportunity for advancing children's vocabulary. E-books go beyond the written text and (static) illustrations and integrate multimedia features such as animations, music, sound effects, illuminated text, and text read out loud by a narrator. Young children before school age can "read" e-books or listen to them independently without an adult's support. Activating e-books that incorporate a built-in dictionary for challenging words may offer young children the opportunity to enrich their vocabulary. 
As researchers who focus on young children's early literacy and language enrichment, we developed e-books with a dictionary aimed at extending young children's word learning. In these e-books, a difficult word that appears in the text is explained orally by the narrator after the narrator finishes reading the text on the screen, and a static figurative representation of the word's meaning appears simultaneously on the screen. A series of studies using e-books with the dictionary format, which we developed with children aged 4-7 (Korat \& Blau, 2010; Korat, Levin, Atishkin, \& Turgeman, 2014; Korat, Levin, Ben-Shabat, Shneor, \& Bokovza, 2014; Korat \& Shamir, 2008; 2012; Shamir, Korat, \& Fellah, 2012), showed that three to five reading sessions of these e-books improved new word learning by children.

\subsection{Learning New Words}

New words can become part of the child's vocabulary through direct learning by exposure to explanations (or dictionary definitions) or through indirect learning from the context in which they appear (Penno, Wilkinson, \& Moore, 2002). Schatz and Baldwin (1986) found that the reading context alone did not support children's learning of infrequent words, and the children exhibited confusion when providing their explanations. According to Swanborn and Gloppers (1999), the ability to learn words from context depends on the learners' ability, grade level and the text density. They found that children with a lower level of language do not learn much from indirect teaching. These studies have shown that although words may be learned from the context, this learning is usually less effective. Contexts can be complicated and may not contain appropriate information for deriving word explanations. These findings led to a direct approach of vocabulary teaching (see McKeown \& Beck, 2004). The idea is that multiple exposures are not enough for learning new words, and planned instructional interventions are required. Researchers assume that a full understanding of the word needs a combination of both providing information from the context and the dictionary definition of the word. The appearance of the word in context provides a specific meaning of the word, and the provision of the dictionary definition expands its meaning by providing the general meaning (Bolger, Balass, Landen, \& Perfetti, 2008; Penno, Moore, \& Wilkinson, 2002).

In our previous study (Korat \& Shamir, 2012), we examined the effectiveness of a direct teaching of words among kindergartners using an e-book with a dictionary, compared to learning new words which appeared in the story without dictionary support. The results showed that the new words which received a dictionary support were learned significantly better than those which did not receive this support. New word learning examined in this study focused solely on the receptive level. In the present study we examined the contribution of direct and indirect instruction of new words in the e-book on the receptive as well as the expressive levels.

\subsection{Receptive and Expressive Vocabulary}

Knowing the meaning of a word has different levels that incorporate receptive knowledge and word production. Receptive vocabulary refers to children's ability to identify the meaning of words to which they are exposed. In many cases it is measured by the child's ability to recognize the word's meaning by pointing to its pictorial representation from among other representations (for example in the PPVT test, Dunn, Dunn, Bulheller, \& Häcker, 1965). Expressive vocabulary refers to the child's ability to use the word in a suitable context and explain it when needed (Sénéchal \& LeFevre, 2002). Studies suggest that verbal knowledge is acquired progressively, from a receptive to an expressive level (de Temple \& Snow, 2003; Ouellette, 2006). It is assumed that new words are initially learned on the receptive level, and as the child develops (or after training) they become available for production purposes (Henriksen, 1999).

The few studies that investigated receptive and expressive word learning following e-book reading compared to a printed book reading found no difference in the effect of both types of books for kindergartens' receptive and expressive vocabulary (Korat, Levin, Atishkin, \& Turgeman, 2014; Korat, Levin, Ben-Shabat, Shneor, \& Bokovza, 2014; Silverman, 2013; Takas, Swart, \& Bus, 2014). In the current study we examined children's receptive and expressive vocabulary with reference to the number of repetitions of the e-book reading.

\subsection{Repeated Readings}

Repeated book reading to young children is regarded as an important vehicle for language enrichment (Biemiller \& Boote, 2006; Penno, Wilkinson, \& Moore, 2002). For example, four repeated book readings for preschoolers expanded their learning of new words better than a single reading (Justice, Meier, \& Walpole, 2005; Sénéchal, 1997). Furthermore, young children learn novel words from shared book reading when the same books are read to them repeatedly better than when different storybooks are read to them (Horst, Parsons, \& Bryan, 2011; McLeod \& McDade, 2011).

The contribution of repeated reading to the child's vocabulary after using e-books was researched in a few studies (Korat \& Shamir, 2012; Silverman 2013; Smeets \& Bus, 2012; Verhallen, Bus \& de Jong, 2006). For example, Silverman (2013) examined kindergartners' reading an e-book three times compared to a single reading. She found that three reading sessions yielded better support for expressive vocabulary compared to a single reading. However, this was not the case for receptive word learning. These results differ from our findings (Korat, 2009) which showed that five 
readings of an e-book with a dictionary supported kindergartners' receptive word learning more than three readings. The research results thus do not offer a clear picture of the contribution of repeated readings to the different levels of vocabulary. In addition, no study has to date examined the effect of repeated exposure to word meanings on new word learning by repeating word explanations using a digital dictionary within the story reading or by repeatedly reading the entire story again with a dictionary. This question is important for two reasons. First, it is interesting to examine whether providing a new word explanation in the story reading context demands reading the overall content again each time, or whether providing the context once is enough and word learning may benefit from the dictionary repetition only. The second reason is more pragmatic. Young children, especially those with low language and literacy ability (for example, children from a low socioeconomic status - LSES), can tire and become less cooperative with a repeated activity on the computer. Repeating the dictionary activation only and not the entire story may work better for these children. The question is, whether this strategy will be efficient for teaching new words to children from a LSES.

In conclusion, in the present study we examined the contribution of a dictionary within a story e-book reading to receptive and expressive new word learning among kindergartners from a LSES. Testing the learning of new words was performed using a direct explanation of the words given to the children in the e-book dictionary and using new words that appeared in the story but did not receive dictionary support. The children read the story twice, and in each reading they received the meaning of the difficult words three times through the dictionary. By doing so, we examined whether the number of repetitions of dictionary words (three versus six) influenced new word learning. We also examined the effect of the repeated readings on the types of words (those which received the dictionary support and those which did not receive the dictionary support) and on the type of learning (receptive learning, explaining and producing words). Children from the experimental group were compared to a control group that received the regular kindergarten program and did not work with an e-book.

\section{Method}

\subsection{Participants}

The participants included 78 Hebrew-speaking kindergartners (aged 5-6) from a low socioeconomic status (LSES). Neighborhood SES levels were determined according to the Israeli Municipalities' Statistical Report (Central Bureau of Statistics, 2008). The children were randomly divided into two groups: experimental $(n=40)$ and control $(n=38)$. In the regular Israeli kindergarten program, kindergarten teachers frequently read storybooks to the children. The children also voluntarily browse through books. Magnetic or other types of Hebrew letters, printed texts for functional use, as well as other texts are displayed around the kindergarten room. Children participate in games aimed at promoting phonemic awareness, such as segmenting words into syllables, counting syllables, and rhyming. Little time is devoted to the recitation of the alphabet or to letter naming. Work sheets for training visual discrimination (including letter discrimination) and letter copying are available (Shatil et al., 2000). Kindergartens usually have 1 to 2 computers, and the children use educational software installed in them, with limited access to e-books. Formal instruction in reading and writing begins upon entry to school at the age of 6-7 years.

\subsection{Procedure}

In the pretest, we examined receptive comprehension of words, explaining words and producing words that appeared in the story. Two reading sessions with each child took place in the experimental group during the intervention stage. In each session, the child read independently from an e-book that automatically provided the meaning of difficult words in the story. After receiving the meaning of the word, the child was requested to press on the dictionary word, and the word meaning was provided once again. This process was repeated twice, so that in each session the child heard the meaning of the word three times. At the end of each session the child was assessed by the same set of tests which was administered during the pretest. In other words, the first posttest was held after the word and its meaning were presented three times and the second posttest was held after the word and its meaning were presented for a total of six times. Ten of the overall assessed difficult words in the story were explained by the dictionary. Eight additional difficult words that appeared in the text did not receive a dictionary explanation. The children in the control group participated in the regular kindergarten program and were assessed at the same time as the children in the experimental group during pretest, posttest 1 and posttest 2 .

\subsection{Research Tools}

\subsubsection{The E-book Book}

The e-book used in this study is an electronic version (Korat, Shamir, \& Segal-Drori, 2005) of Yuval Hamebulbal (Confused Yuval) by Miriam Roth (2000). The story's protagonist is Yuval, a young boy who tends to be confused and forgetful until his grandmother makes a special hat for him to help him remember. A large color drawing covering more than half of the page appears on each of the book's 15 pages, as do 3 to 5 written sentences totaling about 40 words. The 
written text is printed in dotted letters (nekudot in Hebrew), so that the children can also relate to the printed text. The story's structure and simple narrative elements - setting, characters, goal/initiating event, problem and solution/ending (Mandler \& Johnson, 1977) - appear eminently suitable given the participants' age. In the current study we focused on the "Read story with dictionary" mode of the e-book, which offers an oral reading of the text together with explanations of difficult words ( 10 words) that appear automatically on the screen after the entire page has been read by the narrator (the children can reactivate these words). Each difficult word is enunciated clearly by the narrator as it appears on the screen and is associated with pictures that support its meaning.

\subsection{Children's Vocabulary Level}

\subsubsection{Receptive Comprehension}

As in the PPVT test (Dunn \& Dunn, 1981), the children were asked to choose the illustration that best represents the word's meaning out of a set of four illustrations ( 1 point for each correct answer). We used 18 words, where 10 were from the e-book's dictionary mode and 8 appeared in the text, but did not receive dictionary support. Both groups included verbs (e.g., to sweeten or to stretch), nouns (e.g., chameleon or loop) and adjectives (e.g., perfect or wonder). The words were judged to be relatively difficult for children of this age by 3 kindergarten teachers and 2 mothers. The total score for this task ranged from 0-18. The inter-rater reliability for this measure across two raters using Cohen's kappa was .86. Internal reliability assessed by Cronbach's alpha was .54 .

\subsubsection{Word Explanation}

The children were presented orally with the 18 above mentioned target words, one at a time, and were asked to explain their meaning. For example, the child was asked: "What is the meaning of 'lulaha' (loop)?" Two examples were provided prior to testing. The children's responses were coded according to an ordinal scale ranging from 1 to 5 . A child who provided no answer or a wrong answer received 1 point. A child who explained the word by a phonologically similar word was awarded 2 points. For example, a child explained that 'lulaha' (buttonhole) is 'haftaha' (surprise) (both in Hebrew end with "aha"). This response suggests that the child is aware that in Hebrew, due to its root-based morphology, phonological similarity often occurs between semantically close words. A child who explained the word by using it in a suitable context was awarded 3 points. For example, a child explained that 'lulaha' is a tie on a shoe. A child who explained the word by using a synonym or an appropriate short explanation was awarded 4 points. For example, a child who replied that 'lulaha' means "rounding". A child was awarded 5 points if his/her explanation was the one supplied by the dictionary. For example, a child who replied that 'lulaha' means a buttonhole. The inter-rater reliability for this measure across two raters using Cohen's kappa was .84. Internal reliability assessed by Cronbach's alpha was .68 .

\subsubsection{Word Production}

This test measured children's use of new words that appeared in the e-book in story retelling. The children were asked to retell the story using the hardcopy version of the e-book Yuval Hamebulbal (Confused Yuval). This version had only the illustrations of the book without the printed text. The children were asked to retell the story, rather than to read it, since they were non-readers. The children were told: "Here is the book Yuval Hamebulbal that you are already familiar with. Please, retell the story to me page after page. Do it as best as you can". The children's retelling was audio-taped and later transcribed. The transcriptions were coded by counting the number of target words that the child utilized, either in the exact form as they appeared in the text or in an inflected or derived form based on the same root (for example, "they hid" התחבא was exchanged with "he hid"). The score range was 0-18. The inter-rater reliability for this measure across two raters using Cohen's kappa was .77. Internal reliability assessed by Cronbach's alpha was .81. Since we used a different number of words from the e-book's dictionary mode (10) and words that appeared in the text without explanation (8) in the receptive words' measure and in words production, we used a scale of 0 to 100 for these two measures.

\section{Results}

Three two-way ANCOVA analyses were conducted according to groups (intervention/control) and time (pretest, posttest 1 , post-test 2) in order to determine whether the differences between the pre- and post-interventions vocabulary scores resulted from reading the e-book. Table 1 presents means of receptive word comprehension, word explanation and production, pre- and post-intervention, as well as the results of the ANCOVA analyses. The results are also illustrated in Figures 1-3. 
Table 1. Means (and Standard Deviations) of Word Scores by Time and Group

\begin{tabular}{|c|c|c|c|c|c|c|c|c|c|}
\hline \multirow{2}{*}{\multicolumn{2}{|c|}{ Measure }} & \multicolumn{3}{|c|}{ Intervention } & \multicolumn{3}{|c|}{ Control } & \multirow[t]{2}{*}{$\mathrm{F}(2,152)$} & \multirow[t]{2}{*}{$\eta^{2}$} \\
\hline & & Pre & Postl & Post 2 & Pre & Postl & Post2 & & \\
\hline Receptive word & $M$ & 68.20 & 80.14 & 82.34 & 66.52 & 63.60 & 59.00 & $49.81^{* * *}$ & .39 \\
\hline comprehension & $(S D)$ & (13.43) & $(14.50)$ & (17.37) & (12.22) & (11.82) & (13.64) & & \\
\hline Word & $M$ & 2.90 & 3.21 & 3.35 & 2.98 & 2.90 & 2.70 & $86.86 * * *$ & .53 \\
\hline explanation & (SD) & $(0.27)$ & $(0.30)$ & $(0.36)$ & $(0.43)$ & $(0.39)$ & $(0.42)$ & & \\
\hline Word & $M$ & 6.40 & 9.45 & 15.80 & 6.60 & 5.70 & 5.30 & $28.83^{* * *}$ & .27 \\
\hline production & (SD) & $(5.30)$ & $(5.22)$ & $(8.40)$ & $(7.06)$ & $(6.52)$ & $(5.32)$ & & \\
\hline
\end{tabular}

$* * * \mathrm{P}<.001$, Note: Range of receptive word comprehension scores $=0-100$, Range of word explanation scores $=1-5$, Range of word production $=0-18$.

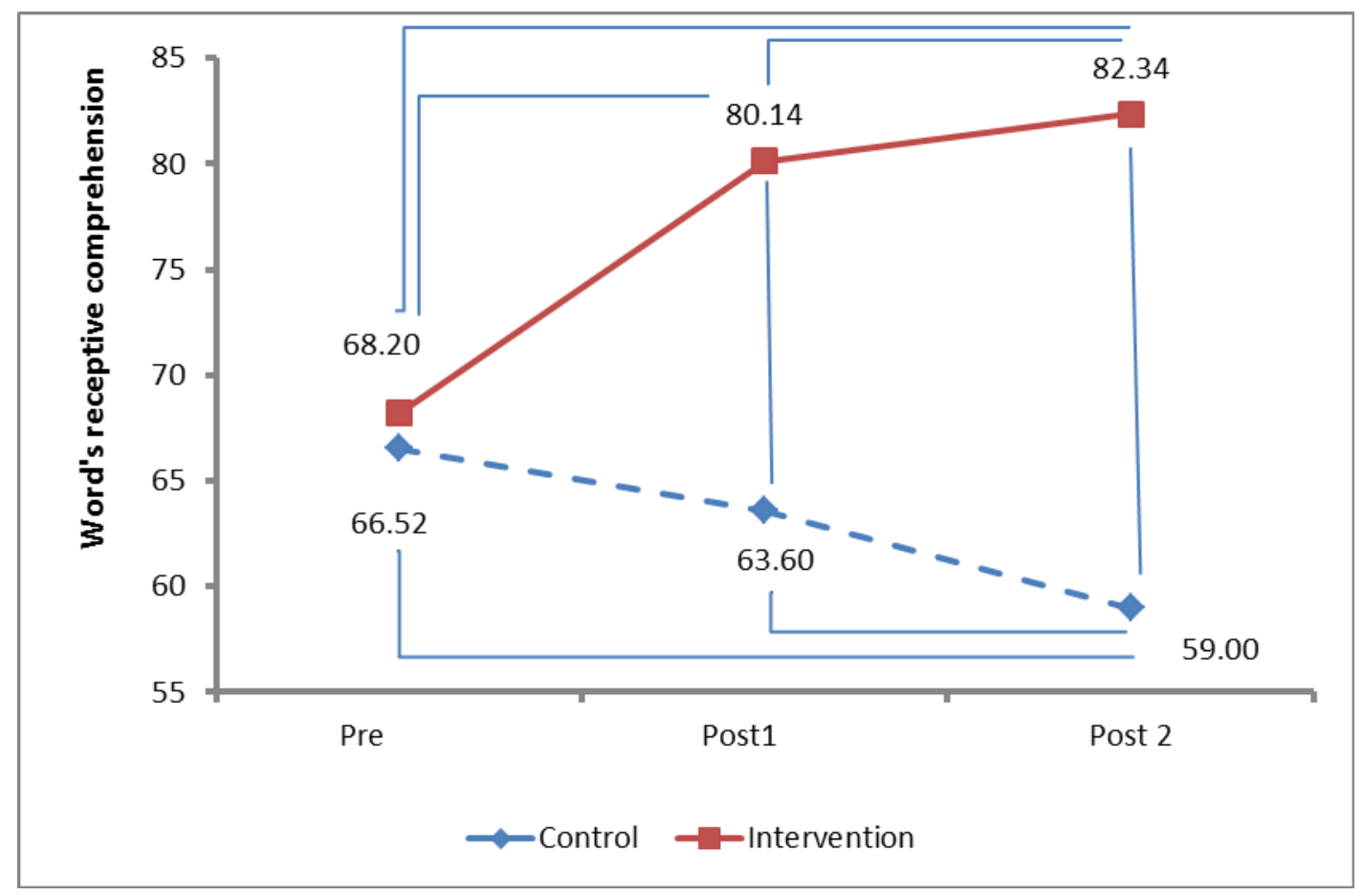

Figure 1. Receptive Comprehension Score: Interaction by Groups and Time 


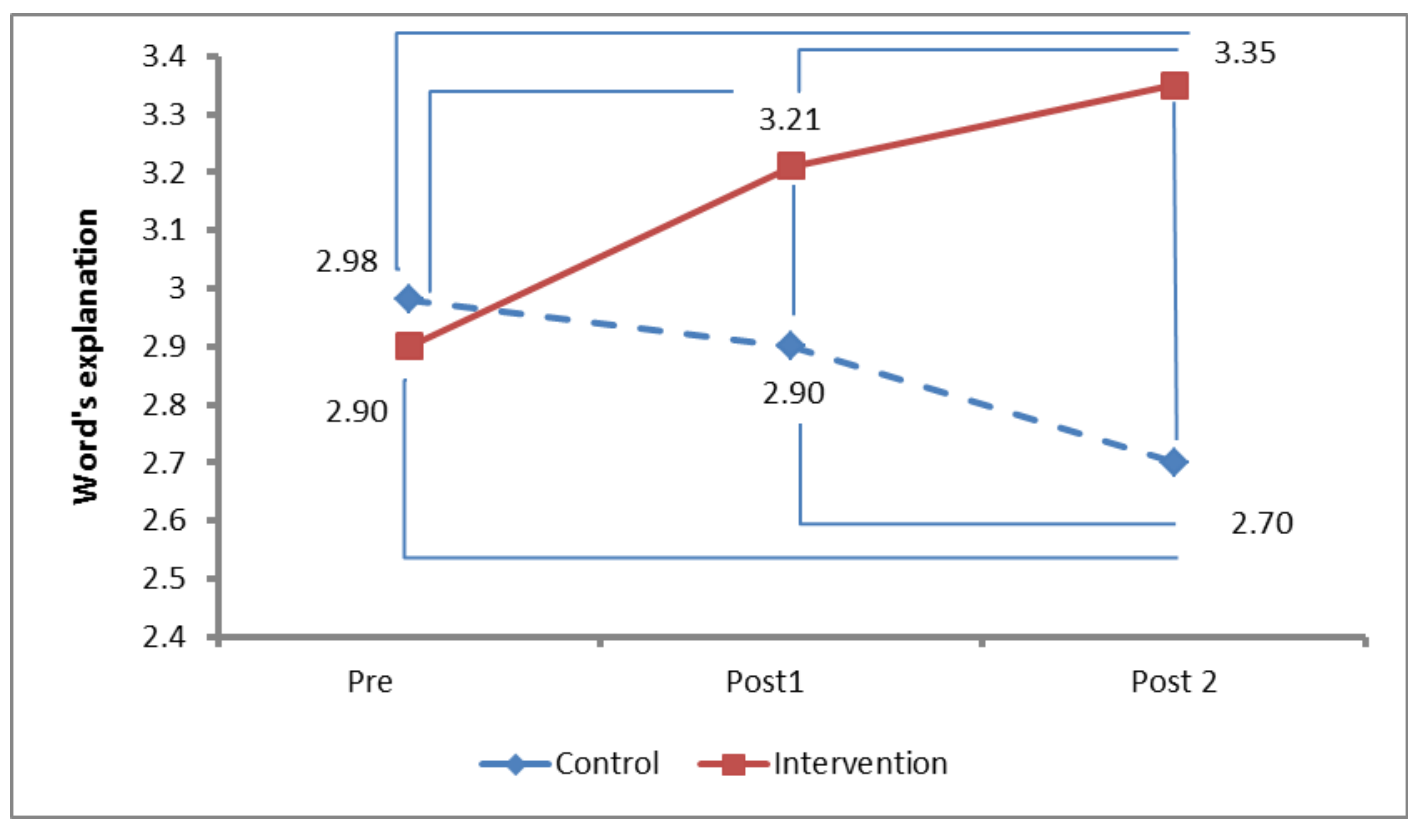

Figure 2. Word Explanation Score: Interaction by Groups and Time

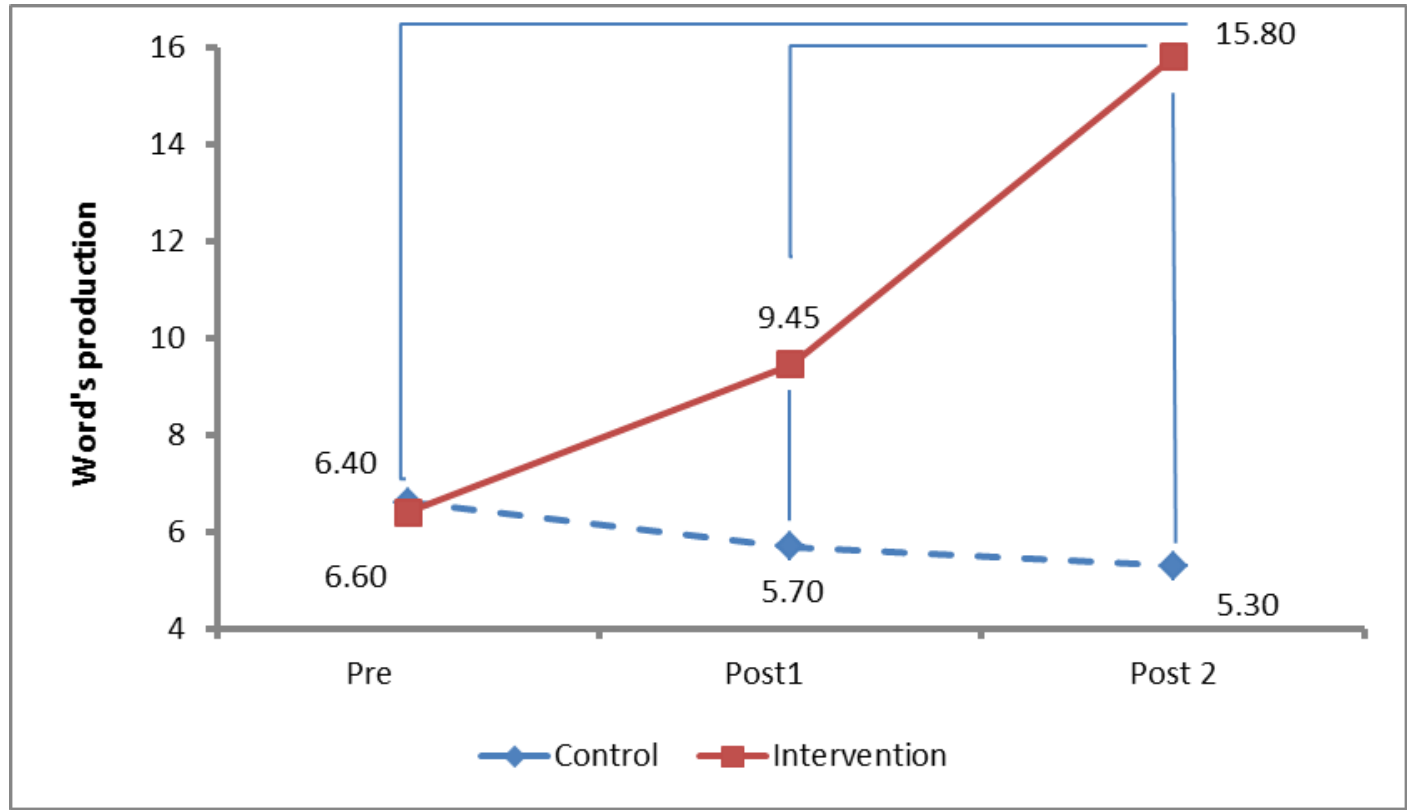

Figure 3. Word Production: Interaction by Groups and Time

As can be seen from Table 1, significant differences were found between the pre- and post-intervention scores in all three measures (receptive word learning, explanation and production of words) between the experimental and the control groups, favoring the experimental group. Children in the experimental group showed significant improvement between the pretest to posttest 1 and between postest1 to posttest 2 in receptive word comprehension and word explanation. Progress also appeared between the pretest to posttest 2 in these two measures. In contradistinction, no differences in these measures were found among the control group between the pretest and posttest 1 , and a significant decrease was observed from posttest 1 to posttest 2 . Furthermore, a significant decrease was found from the pretest to posttest 2 in both groups $\left(F(2,152)=49.81, p<.001, \mathrm{\eta}^{2}=.39, F(2,152)=86.86, p<.001, \eta^{2}=.53\right)$.

No significant progress in word production was found between the pretest and posttest 1 in the experimental group. However, significant progress was found between posttest 1 and 2 , and between the pretest and posttest 2 . No differences were found between the pretest and posttest 1 , between posttest 1 and posttest 2 and between the pretest and posttest 2 in the control group $F(2,152)=28.83, p<.001, \eta^{2}=.27$ ).

Three two-way ANCOVA analyses were conducted in order to compare the progress of children who received dictionary support (intervention group) to those who did not receive dictionary support (control group): 2 
(intervention/control) X 3 (time- pretest, posttest 1, posttest 2) X (type of word - with dictionary support/without dictionary support). Table 2 presents the results of these analyses regarding each vocabulary measure. The results are also illustrated in Figures 4-6.

Table 2. Word Scores (and Standard Deviations) with and without Dictionary Support by Time and Group

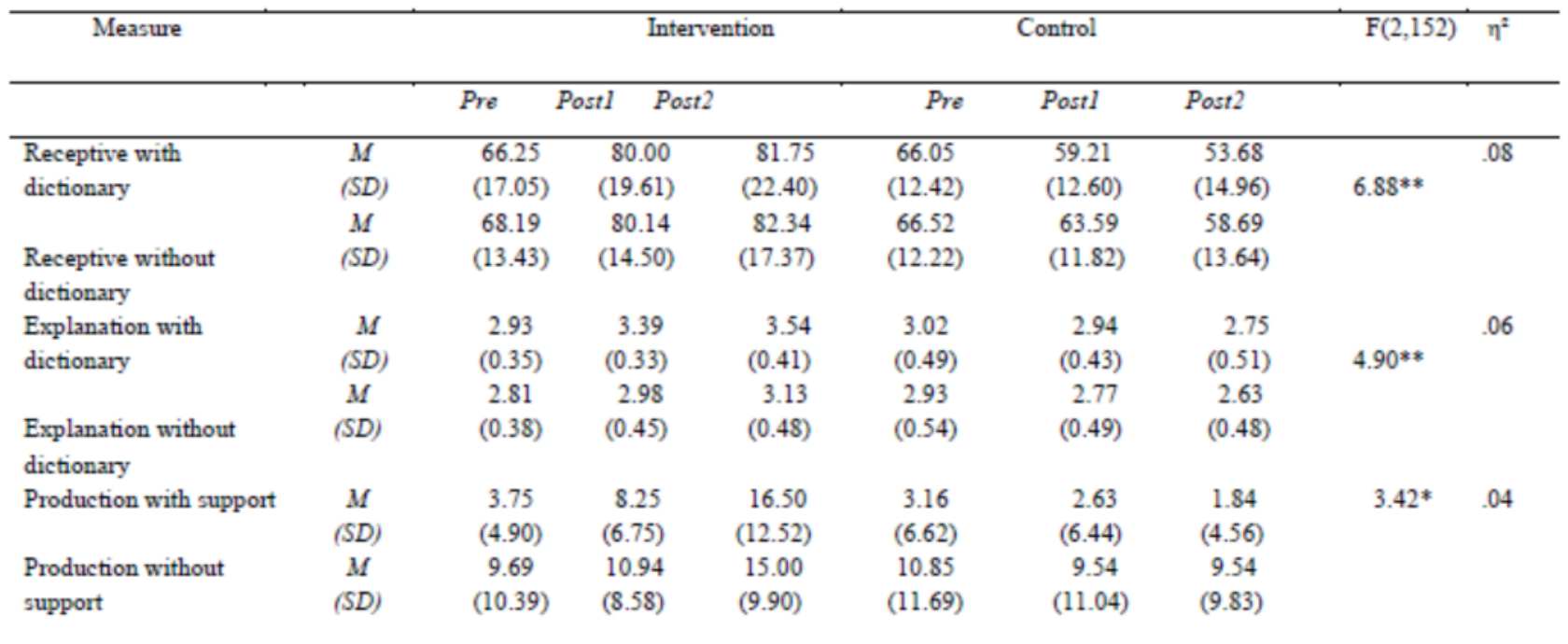

$* \mathrm{P}<.05, * * \mathrm{P}<.01, * * * \mathrm{P}<.001$, Note: Range of receptive word comprehension scores $=0-100$, Range of word explanation $=1-5$, Range of word production $=0-18$

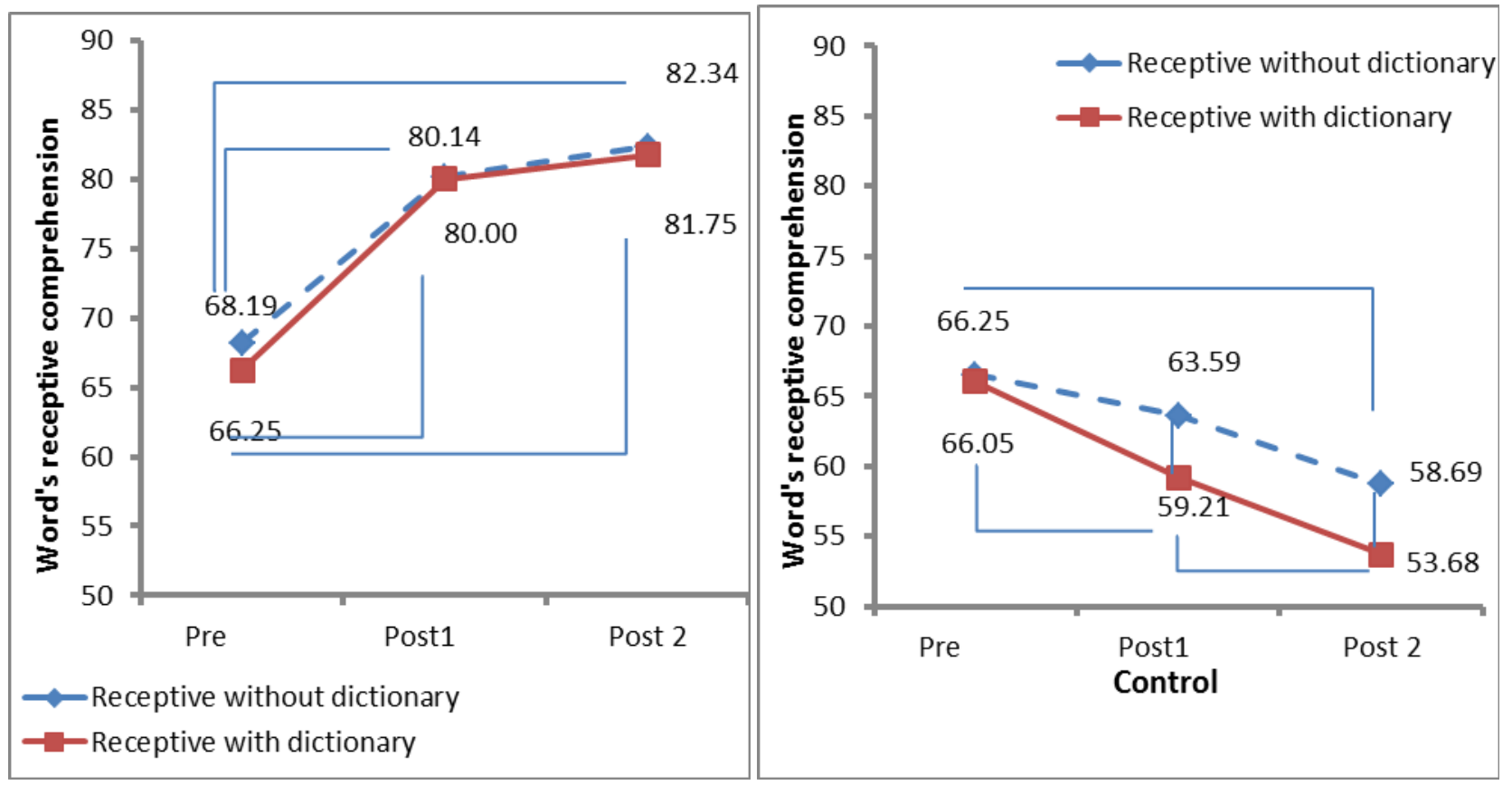

Figure 4. Receptive Word Comprehension Score: Interaction by Groups, Time and Type of Word 


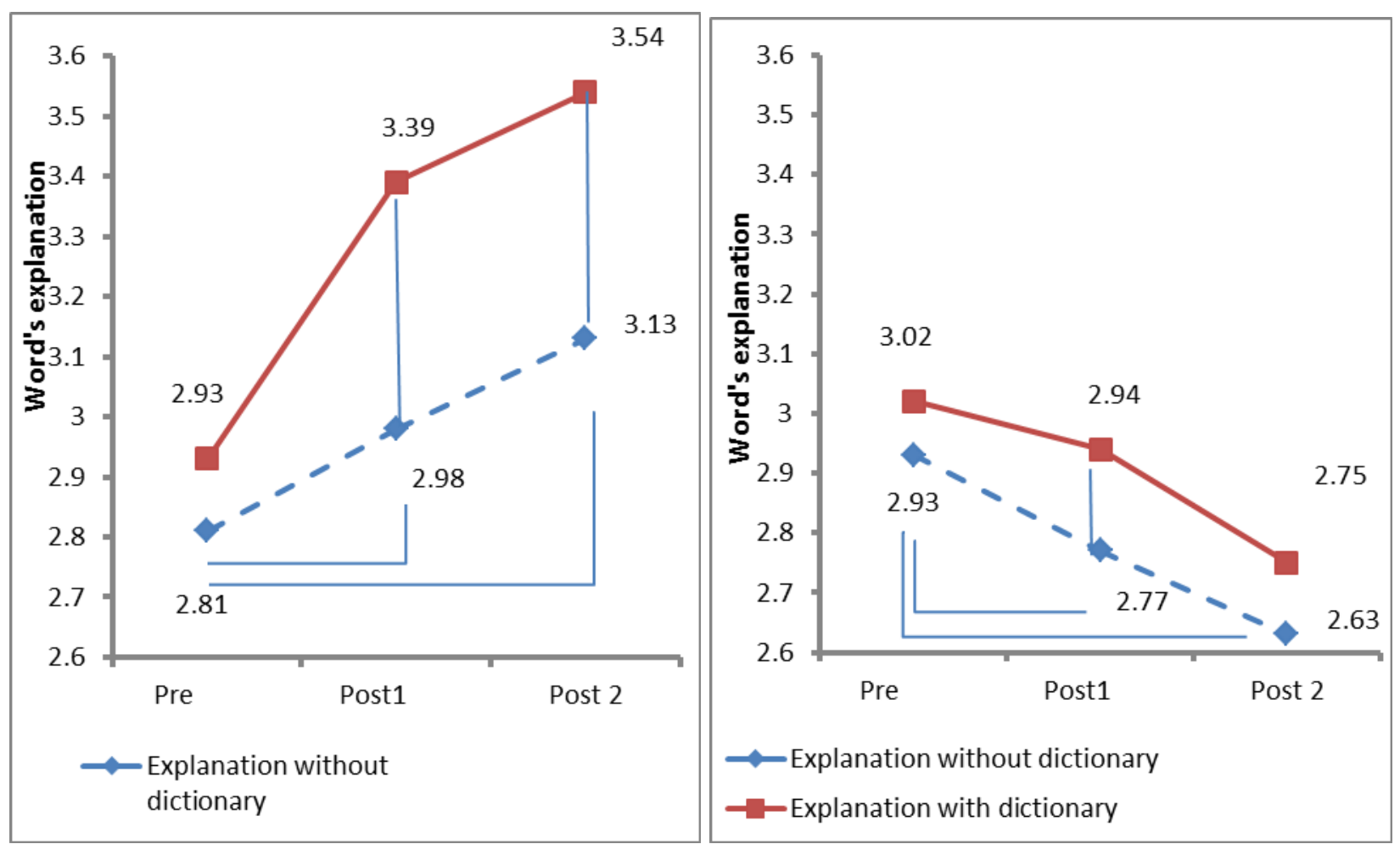

Figure 5. Word Explanation Score: Interaction by Groups, Time and Type of Word
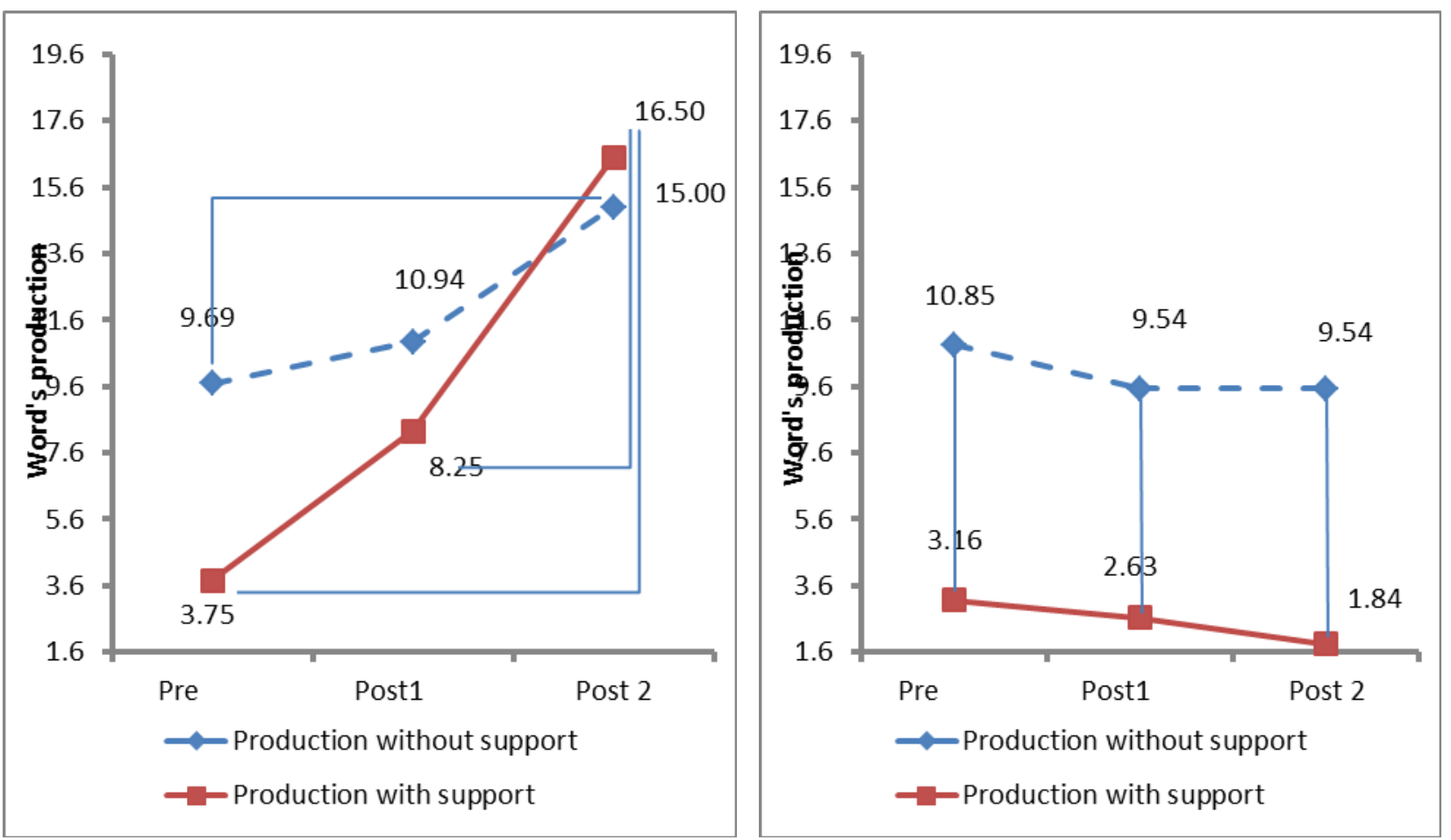

Figure 6. Word Production Interaction by Groups, Time and Type of Word 
Regarding receptive comprehension of words in the experimental group, words supported by a dictionary as well as those which did not receive the support improved from the pretest to posttest 1, but further progress was not found between posttest 1 and posttest 2 . In addition, significant progress was found between the pretest and posttest 2 . Dictionary words in the control group were significantly lower from the pretest to posttest 1 , from posttest 1 to posttest 2 and from the pretest to posttest 2. However, words which did not appear in the dictionary showed no significant difference between the pretest and posttest 1 , and between posttest 1 and posttest 2 , while there was a significant decrease between the pretest and posttest $2\left(F(2,152)=6.88, p<.01, \eta^{2}=.08\right)$.

In the experimental group, a significant difference in the explanation of words was found in posttest 1 and posttest 2 in favor of dictionary words compared to non-dictionary words. Significant progress was found for dictionary and non-dictionary words between the pretest and posttest 1 , but further progress was not found between posttest 1 and posttest 2. In addition, significant progress was found between the pretest and posttest 2 . In the control group, a significant decrease in explanation of dictionary words was found from the pretest to posttest 1 , but the scores from posttest 1 to posttest 2 and from the pretest and posttest 2 remained the same. However, words which were not explained in the dictionary showed a significant decrease between the pretest and posttest 1 , and no differences were found between posttest 1 and posttest 2 , while there was a significant decrease between the pretest and posttest 2 $\left(F(2,152)=4.90, p<.01, \eta^{2}=.06\right)$.

A significant difference in word production was found in the pretest between words which were in the dictionary and words which were not in the dictionary, favoring words not in the dictionary. In the experimental group, dictionary words showed no significant progress from the pretest to posttest 1 , but significant progress was found between posttest 1 and posttest 2 and between the pretest and posttest 2. No significant progress was found for words which were not in the dictionary between the pretest and posttest 1 and between posttest 1 and posttest 2 , but there was significant progress between the pretest and posttest 2. No difference in word production was found between the experimental group and the control group in the change in the children's score from the pretest to posttest 1 , from posttest 1 to posttest 2 and from the pretest to posttest $2\left(F(2,152)=3.42, p<.05, \eta^{2}=.04\right)$.

\section{Discussion}

The research findings show that children who read the e-book learned more new words than the children in the control group, who did not read the e-book. This was the case in all three levels: receptive word learning, explanation and production of words. This finding is consistent with previous results showing that kindergartners' independent reading of an e-book can enhance their learning of new words (Shamir, 2009; Silverman, 2013; Takas, Swart, \& Bus, 2014). The findings on whether new word learning depends on providing its meaning in the story, or whether it occurs following its appearance in the text, were mixed. No difference in the receptive level was found between dictionary and non-dictionary words. The findings show that identifying words' meaning by pictures was possible when the children were exposed to the story without the dictionary. Exposure to the dictionary definition, which provides their core meaning, is apparently not essential for progress in this partial understanding (the receptive level). This finding is consistent with results from previous studies showing that repeated exposure to a new word in context may lead to significant learning (Durso \& Shore, 1991; Elshout-Mohr \& van Daalen-Kapteijns, 1987).

For word explanation, the children exhibited better explanations of new words that received dictionary support compared to those that did not receive this support. However, it should be noted that progress was also significant for non-dictionary words, although in this case it was significantly smaller. These findings suggest that the ability to explain words best improves when the word is given a direct explanation while listening to the story. However, exposure to the word in the story context several times might teach the child to explain the word, even though progress in this situation is smaller. These results extend our knowledge on the support of a dictionary in e-books for word learning, and show that such a dictionary may support kindergarteners not only in receptive word learning (Korat \& Shamir, 2012), but also in word explanation.

No differences in the production level were observed for dictionary and non-dictionary words, in the two posttest measures. These findings show similar progress for both types of words. However, a closer examination shows that in the pretest, the ability to produce the words which were in the dictionary was particularly low compared to those which did not receive dictionary support. In fact, the children progressed in both types of words, and much progress was made in the dictionary words (which was initially very low), such that it closed the initial gap compared to the words which were not supported by the dictionary.

It is important to note that the children in the control group, who participated in the regular kindergarten program, also exhibited a gap in the pretest in favor of production of the words without dictionary support compared to those with support. This difference remained throughout all the study phases. Since we cannot give a definite answer to the research question about the effectiveness of promoting the production of words, we suggest looking at our results as a 
possible support for word explanation and as a way to promote the ability to use it. This assumption will have to be examined in future studies.

The current study extends the findings in the literature by relating to three levels of word learning, and by examining direct/indirect teaching of these levels. It seems that young children can progress in basic word understanding (receptive level) by being exposed to the words in the oral text similarly to being exposed to their meaning while listening to the story. However, more significant progress in the overall ability to explain the word is achieved after exposure to the core meaning of the word. A significant difference was found in the production of new words in the initial level of words that appear in the dictionary compared to those which are not included in the dictionary.

Some explanations for why substantial progress was made after reading the e-book with the dictionary for the task of explaining the words compared to receptive understanding and compared to production knowledge can be suggested. The first possible explanation is the similarity between the support which was given by the dictionary and the word explanation task that the children were given. The dictionary gave an explanation for a word, and the word meaning task examined the child's progress in this task. In contradistinction, the two other measures require different abilities. For example, in the receptive task, the illustrations which the children were asked to select in the test were different from those presented in e-book's dictionary. Also, throughout the e-book activity, the children were not asked to produce their own words, whereas this was required in the production task. A second possible explanation is that the progress in receptive understanding is a relatively easy cognitive demand. Three exposures sufficed for learning the words on this level. On the other hand, active use of the dictionary words and use of the word in a spoken text is a cognitively demanding task, and is beyond the input of the word's explanation and repeating it, as required in the explanation task. The hypothesis that we would find more substantial progress in producing words that received dictionary support compared to words that did not, if the difficulty level of the word production was similar in both conditions, could not be verified, since the children's level of these two groups of words was different from the beginning. We therefore cannot determine, from this study, whether a higher level of difficulty, such as the ability to produce words, would have made a significant contribution without explaining difficult words. This question requires further research in order to provide an appropriate answer.

Since more significant progress in the overall ability to explain the word was achieved after exposure to the core meaning of the word by the dictionary, the findings about the number of repetitions of the dictionary explanation is meaningful only for the children's word explanation level. The findings show that there was significant progress in the ability to explain new words from the story after three repetitions of the dictionary words, and after three additional repetitions (six in total) the children achieved further progress. These findings indicate the strength of the presentation of the lexical meaning of the difficult words alone, without repetition and reading the entire story again. It is important to mention that during the course of the reading, the children clicked on the automatic meaning of the word two more times while reading the book (i.e., the meaning was given 3 times), and there were not three readings of the full story every time. Although explaining words can be a complex cognitive ability for young children, three repetitions of the new word meanings led to significant advances in this skill. In addition, re-reading of the story that included three more repetitions of the meaning of the word led to further progress in this skill. These findings are consistent with the findings of previous studies, which showed a positive effect of the number of repetitions for improving various literacy measures (Korat \& Blau, 2010; Silverman, 2013; Verhallen et al., 2006). Silverman (2013), for example, found that three reading sessions yielded better support for expressive vocabulary compared to a single reading, but this was not the case regarding receptive word learning. Korat (2009) found that five repetitions of the e-book led to greater progress in receptive word learning compared to three repetitions with the e-book and three repetitions led to greater advances than the control group that did not read the e-book. In more cognitively complex emergent literacy measures such as word reading and phonological awareness, three repetitions of the e-book were not enough and it took five repetitions to see progress.

To the best of our knowledge, this study is the first to examine the impact of the number of repetitions of dictionary words in reading a story without rereading the entire story on the child's new word learning on three levels. The unique finding of this study is that three repetitions of the dictionary words are enough for progress in explaining words, and three more repetitions bring further progress. If the purpose of the reading is to enrich vocabulary, it is possible that there is no need to repeat the entire story reading several times, and perhaps repeated exposure to the word's meaning by the dictionary will be sufficient for this purpose. Rereading the story many times may sometimes be demanding and boring for some children, and this might also reduce their cooperation (see for example, de Jong \& Bus, 2003). Short and focused repetition of the meaning of words in the story context may require fewer cognitive resources, but still facilitate new words learning. However, if the goal is not only to promote the understanding of new words, but also to work on story comprehension, it is necessary to test whether this strategy is suitable. This point was not examined in this work and should be examined in further studies. 
Some limitations of the current research should be noted. First, the unexpected different level between word production of dictionary words compared to non-dictionary words necessitates better word selection (e.g., word frequency, nouns, verbs) in future studies, especially for demanding tasks such as word production. It is also recommended that future studies examine whether children's progress after the e-book activity is maintained over time. In the current study the children were tested immediately after the e-book activity. It is possible that a posttest after a longer period of time (about 4 to 6 weeks) will show that the words which were given in the dictionary support were assimilated better among the children over time and their learning was maintained compared to words that did not receive dictionary support (see for example, Arest, 2012).

In conclusion, since e-books are today ubiquitous in schools and homes and are attractive to young children, educators and software designers should regard them as a possible tool for promoting language and literacy. The present study shows how children's word explanation ability was supported by a built-in dictionary in an e-book, and the effects of repetitions of this dictionary. Furthermore, this occurred with young children "reading" these e-books by themselves without adults' help. We recommend that policymakers and educators incorporate quality e-books in order to promote children's language and early literacy. Moreover, beyond e-book reading, this study points to the importance of providing word meanings to young children in shared adult-child reading activities. Although children can understand words out of the context (usually at relatively low levels), word understanding can be supported at a higher level when an explicit support is given in the story context.

\section{References}

Arest, K. (2012). The impact of maternal mediation on kindergarten children's reading following book reading: A comparison between printed book and e-book reading. Thesis submitted to School of Education, Bar-Ilan University. (Hebrew).

Biemiller, A., \& Boote, C. (2006). An effective method for building meaning vocabulary in primary grades. Journal of Educational Psychology, 98(1), 44-62. https://doi.org/10.1037/0022-0663.98.1.44

Bolger, D. J., Balass, M., Landen, E., \& Perfetti, C. A. (2008). Context variation and definitions in learning the meanings of words: An instance-based learning approach. Discourse Processes, 45(2), 122-159. https://doi.org/10.1080/01638530701792826

Bus, A. G., Van Ijzendoorn, M. H., \& Pellegrini, A. D. (1995). Joint book reading makes for success in learning to read: A meta-analysis on intergenerational transmission of literacy. Review of Educational Research, 65(1), 1-21. https://doi.org/10.3102/00346543065001001

de Jong, M. T., \& Bus, A. G. (2003). How well suited are electronic books to supporting literacy? Journal of Early Childhood Literacy, 3(2), 147-164. https://doi.org/10.1177/14687984030032002

De Temple, J., \& Snow, C. E. (2003). Learning words from books. In P. H. Ane Van Kleeck, A. Van Kleeck, S. A. Stahl, \& E. B. Bauer (Eds.), On reading books to children: Parents and teachers (pp.16-36). New-Jersey Lawrence Erlbaum.

Dickinson, D. K., Griffith, J. A., Golinkoff, R. M., \& Hirsh-Pasek, K. (2012). How reading books fosters language development around the world. Child Development Research. https://doi.org/10.1155/2012/602807

Dunn, L. M., Dunn, L. M., Bulheller, S., \& Häcker, H. (1965). Peabody picture vocabulary test. Circle Pines, MN: American Guidance Service.

Durso, F. T., \& Shore, W. J. (1991). Partial knowledge of word meanings. Journal of Experimental Psychology: General, 120(2), 190-202. https://doi.org/10.1037/0096-3445.120.2.190

Elshout-Mohr, M., \& van Daalen-Kapteijns, M. M. (1987). Cognitive processes in learning word meanings. In M. G. McKeown., \& M. E. Curtis. (Eds.), The nature of vocabulary acquisition (pp. 53-71). Hillsdale, NJ: Lawrence Erlbaum.

Evans, M. A., Reynolds, K., Shaw, D., \& Pursoo, T. (2011). Parental explanations of vocabulary during shared book reading: A missed opportunity. First Language, 31(2), 195-213. https://doi.org/10.1177/0142723710393795

Guernsey, L., Levine, M., Chiong, C., \& Severns, M. (2014). Pioneering literacy in the digital Wild West. New York: Joan Ganz Cooney Center at Sesame Workshop.

Henriksen, B. (1999). Three dimensions of vocabulary development. Studies in Second Language Acquisition, 21(2), 303-317. https://doi.org/10.1017/S0272263199002089

Hindman, A. H., Skibbe, L. E., \& Foster, T. D. (2014). Exploring the variety of parental talk during shared book reading and its contributions to preschool language and literacy: Evidence from the Early Childhood Longitudinal 
Study-Birth Cohort. Reading and Writing, 27(2), 287-313. https://doi.org/10.1007/s11145-013-9445-4

Horst, J. S., Parsons, K. L., \& Bryan, N. M. (2011). Get the story straight: Contextual repetition promotes word learning from storybooks. Frontiers in Psychology, 2, 17. https://doi.org/10.3389/fpsyg.2011.00017

Justice, L. M., Meier, J., \& Walpole, S. (2005). Learning new words from storybooks: An efficacy study with at-risk kindergartners. Language, Speech, and Hearing Services in Schools, 36(1), 17-32. https://doi.org/10.1044/0161-1461(2005/003)

Korat, O. (2009). The effects of CD-ROM storybook reading on children's emergent literacy as a function of age group and repeated reading. Education and Information Technologies, 14(1), 39-53. https://doi.org/10.1007/s10639-008-9063-y

Korat, O., \& Blau, H. (2010). Repeated reading of CD-ROM storybook as a support for emergent literacy: A developmental perspective in two SES groups. Journal of Educational Computing Research, 43(4), 445-466. https://doi.org/10.2190/EC.43.4.b

Korat, O., \& Shamir, A. (2008). The educational electronic book as a tool for supporting children's emergent literacy in low versus middle SES groups. Computers \& Education, 50(1), 110-124. https://doi.org/10.1016/j.compedu.2006.04.002

Korat, O., \& Shamir, A. (2012). Direct and indirect teaching: Using e-books for supporting vocabulary, word reading, and story comprehension for young children. Journal of Educational Computing Research, 46(2), 135-152. https://doi.org/10.2190/EC.46.2.b

Korat, O., Levin, I., Atishkin, S., \& Turgeman, M. (2014). E-book as facilitator of vocabulary acquisition: Support of adults, dynamic dictionary and static dictionary. Reading and Writing, 27(4), 613-629.

https://doi.org/10.1007/s11145-013-9474-z

Korat, O., Levin, I., Ben-Shabat, A., Shneor, D., \& Bokovza, L. (2014). Dynamic versus static dictionary with and without printed focal words in e-book reading as facilitator for word learning. Reading Research Quarterly, 49(4), 371-386. https://doi.org/10.1002/rrq.78

Korat, O., Shamir, A., \& Segal-Drori, O. (2005). Confused Yuval- electronic version. Experimental Edition.

Lennox, S. (2013). Interactive read-alouds: An avenue for enhancing children's language for thinking and understanding: A review of recent research. Early Childhood Education Journal, 41(5), 381-389. https://doi.org/10.1007/s10643-013-0578-5

Mandler, J. M., \& Johnson, N. S. (1977). Remembrance of things parsed: Story structure and recall. Cognitive Psychology, 9(1), 111-151. https://doi.org/10.1016/0010-0285(77)90006-8

McKeown, M. G., \& Beck, I. L. (2004). Direct and rich vocabulary instruction. In J. F. Baumann \& E. J. Kame'enui (Eds.),Vocabulary instruction: Research to practice (pp.13-27). New York: Guilford.

McLeod, A. N., \& McDade, H. L. (2011). Preschoolers' incidental learning of novel words during storybook reading. Communication Disorders Quarterly, 32(4), 256-266. https://doi.org/10.1177/1525740109354777

Mol, S. E., Bus, A. G., de Jong, M. T., \& Smeets, D. J. (2008). Added value of dialogic parent-child book readings: A meta-analysis. Early Education and Development, 19(1), 7-26. https://doi.org/10.1080/10409280701838603

National Institute of Child Health and Human Development (NICHD) (2000). Report of the national reading panel: Teaching children to read: An evidence-based assessment of the scientific research literature on reading and its implications for reading instruction: Reports of the subgroups. US: National Institute of Child Health and Human Development, National Institutes of Health.

Ouellette, G. P. (2006). What's meaning got to do with it: The role of vocabulary in word reading and reading comprehension. Journal of Educational Psychology, 98(3), 554. https://doi.org/10.1037/0022-0663.98.3.554

Penno, J. F., Wilkinson, I. A., \& Moore, D. W. (2002). Vocabulary acquisition from teacher explanation and repeated listening to stories: Do they overcome the Matthew effect? Journal of Educational Psychology, 94(1), 23-33. https://doi.org/10.1037/0022-0663.94.1.23

Roth, M. (2000). Confused yuval. Israel: Poalim Publishing (Hebrew).

Scarborough, H. S., \& Dobrich, W. (1994). On the efficacy of reading to preschoolers. Developmental Review, 14(3), 245-302. https://doi.org/10.1006/drev.1994.1010

Schatz, E. K., \& Baldwin, R. S. (1986). Context clues are unreliable predictors of word meanings. Reading Research Quarterly, 21(4), 439-453. https://doi.org/10.2307/747615 
Sénéchal, M. (1997). The differential effect of storybook reading on preschoolers' acquisition of expressive and receptive vocabulary. Journal of Child language, 24(1), 123-138. https://doi.org/10.1017/S0305000996003005

Sénéchal, M., \& LeFevre, J. A. (2002). Parental involvement in the development of children's reading skill: A five-year longitudinal study. Child Development, 73(2), 445-460. https://doi.org/10.1111/1467-8624.00417

Shamir, A. (2009). Processes and outcomes of joint activity with e-books for promoting kindergarteners' emergent literacy. Educational Media International, 46(1), 81-96. https://doi.org/10.1080/09523980902781295

Shamir, A., Korat, O., \& Fellah, R. (2012). Promoting vocabulary, phonological awareness and concept about print among children at risk for learning disability: Can e-books help? Reading and Writing, 25(1), 45-69. https://doi.org/10.1007/s11145-010-9247-x

Shatil, E., Share, D., \& Levin, I. (2000). On the contribution of kindergarten writing to grade 1 literacy: A longitudinal study in Hebrew. Applied Psycholinguistics, 21(1), 1-21. https://doi.org/10.1017/S0142716400001016

Silverman, R. (2013). Investigating video as a means to promote vocabulary for at-risk children. Contemporary Educational Psychology, 38(3), 170-179. https://doi.org/10.1016/j.cedpsych.2013.03.001

Smeets, D. J., \& Bus, A. G. (2012). Interactive electronic storybooks for kindergartners to promote vocabulary growth. Journal of Experimental Child Psychology, 112(1), 36-55. https://doi.org/10.1016/j.jecp.2011.12.003

Sparks, A., \& Reese, E. (2013). From reminiscing to reading: Home contributions to children's developing language and literacy in low-income families. First Language, 33(1), 89-109. https://doi.org/10.1177/0142723711433583

Swanborn, M. S., \& De Glopper, K. (1999). Incidental word learning while reading: A meta-analysis. Review of Educational Research, 69(3), 261-285. https://doi.org/10.3102/00346543069003261

Takacs, Z. K., Swart, E. K., \& Bus, A. G. (2014). Can the computer replace the adult for storybook reading? A meta-analysis on the effects of multimedia stories as compared to sharing print stories with an adult. Frontiers in Psychology, 5, 1366. https://doi.org/10.3389/fpsyg.2014.01366

Verhallen, M. J. A. J., \& Bus, A. G. (2010). Low-income immigrant pupils learning vocabulary through digital picture storybooks. Journal of Educational Psychology, 102(1), 54-61. https://doi.org/10.1037/0022-0663.98.2.410

Verhallen, M. J., Bus, A. G., \& de Jong, M. T. (2006). The promise of multimedia stories for kindergarten children at risk. Journal of Educational Psychology, 98(2), 410-419. https://doi.org/10.1037/0022-0663.98.2.410

\section{Copyrights}

Copyright for this article is retained by the author(s), with first publication rights granted to the journal.

This is an open-access article distributed under the terms and conditions of the Creative Commons Attribution license which permits unrestricted use, distribution, and reproduction in any medium, provided the original work is properly cited. 